\title{
A rare cause of osteomyelitis of distal phalanx: Candida Iusitaniae
}

\author{
Erdinc Acar, MD (1), Ugur Bezirgan, MD (1) \\ Department of Orthopedics and Traumatology, Hand and Upper Extremity Surgery Division, Ankara City Hospital, Ankara, Turkey
}

Osteomyelitis of the metacarpal bones and phalanges accounts for about 1.1 to $10 \%$ of hand infections. ${ }^{[1-4]}$ In the majority of cases with phalangeal osteomyelitis, distal phalanx is the most frequently involved bone. ${ }^{[1]}$ In the literature, osteomyelitis of the phalanges caused by the Candida species (spp.) is rare and many culprits play a role in the development of osteomyelitis; ${ }^{[5,6]}$ however, it is a difficult-to-treat condition with a high morbidity rate. Among Candida spp., Candida albicans is the most common cause of osteomyelitis. ${ }^{[7,8]}$ Osteomyelitis caused by other Candida spp. have been described in case reports in the literature. ${ }^{[9]}$ On the other hand, Candida lusitaniae (C. Iusitaniae) is an uncommon pathogen in osteomyelitis. ${ }^{[10]}$ Risk factors associated with C. Iusitaniae infection include neutropenia, post-trauma, hematological malignancies, the use of cytotoxic drugs or corticosteroids, and the receipt of broad-spectrum antibiotics or central venous catheters. ${ }^{[1,11]}$

Received: October 12, 2020

Accepted: December 08, 2020

Published online: June 11, 2021

Correspondence: Erdinç Acar, MD. Ankara Şehir Hastanesi Ortopedi ve Travmatoloji Kliniği, El ve Üst Ekstremite Cerrahisi Bölümü, 06800 Çankaya, Ankara, Türkiye.

E-mail: erdal240@gmail.com

Doi: 10.52312/jdrs.2021.79490

Citation: Acar E, Bezirgan U. A rare cause of osteomyelitis of distal phalanx: Candida lusitaniae. Jt Dis Relat Surg 2021;32(2):556-559.

(92021 All right reserved by the Turkish Joint Diseases Foundation

This is an open access article under the terms of the Creative Commons Attribution-NonCommercial License, which permits use, distribution and reproduction in any medium, provided the original work is properly cited and is not used for commercial purposes (http://creativecommons.org/licenses/by-nc/4.0/).

\section{ABSTRACT}

Osteomyelitis of the phalanx caused by Candida species are rare. A 49-year-old female patient was admitted to an external center with a splinter injury of the third phalanx of the middle finger of her left hand about 45 days ago. She was referred to our clinic with persistent pain and discharge, despite four-week antibiotherapy. Debridement and curettage were performed and partial excision of the distal phalanx at an appropriate level was done. Her complaints gradually resolved postoperatively with prescribed antibiotics for the pathogen identified as Candida lusitaniae based on the intraoperative cultures. At her three-month follow-up visit, treatment yielded near-excellent results. To the best of our knowledge, this is the first case of osteomyelitis of the distal phalanx caused by Candida lusitaniae in the literature, highlighting the importance of definitive diagnosis and pathogen-specific treatment, rather than empirical treatment, to achieve favorable results with cure.

Keywords: Antibiotherapy, candida lusitaniae, debridement, distal phalanx, osteomyelitis.

Treatment of osteomyelitis mainly involves early diagnosis, adequate antibiotherapy, and surgery. The latter has a wide range of procedures including debridement, curettage, arthrodesis, joint reconstruction, and amputation. ${ }^{[1,12,13]}$ In this report, we present the first case of osteomyelitis of the distal phalanx caused by $C$. Iusitaniae in the literature and discuss its diagnosis and treatment in the light of current data.

\section{CASE REPORT}

A 49-year-old female patient was admitted to an external center with a splinter injury (piece of wood) of the third phalanx of the middle finger of her left hand about 45 days ago. She was referred to our clinic with persistent pain and discharge, despite four-week antibiotherapy (amoxicillin/clavulanic acid $1000 \mathrm{mg}$, PO, b.i.d.) (Figure 1). Laboratory test results were as follows: white blood cell (WBC) count $11,750(3,900-10,200) / \mathrm{mm}^{3}$, erythrocyte 


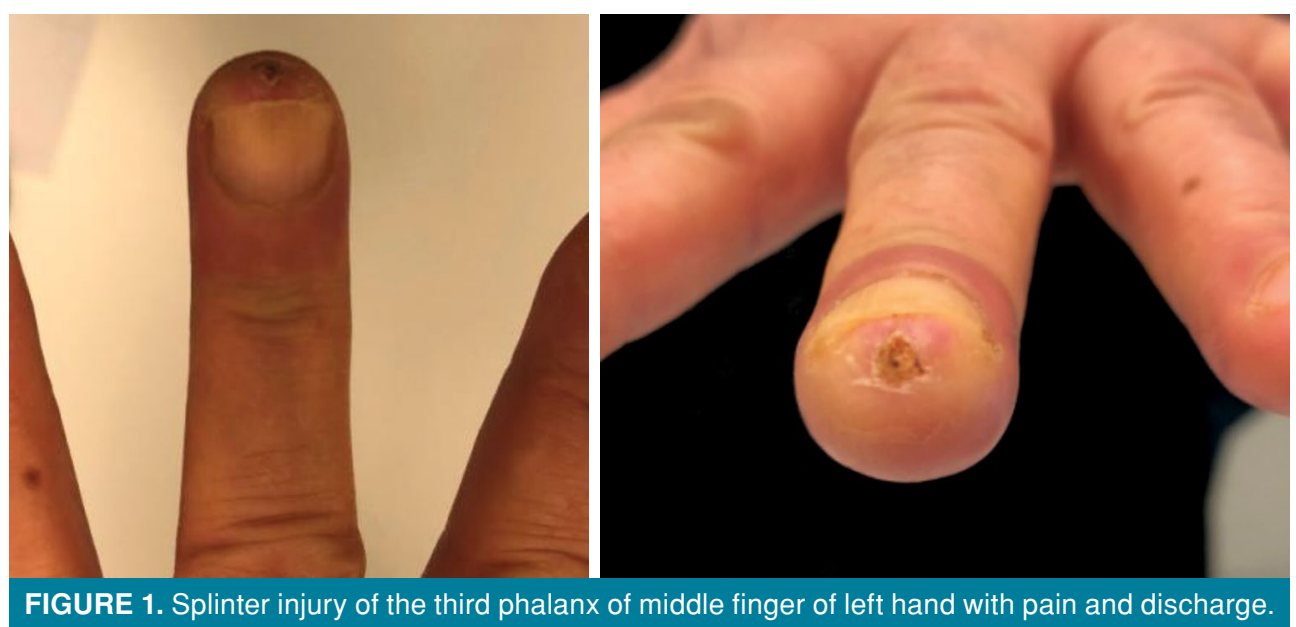

sedimentation rate (ESR) $17(0-20) \mathrm{mm} / \mathrm{h}$, and C-reactive protein (CRP) 0.000785 (0-0,005) g/L. Physical examination and radiographs revealed osteomyelitis of the distal phalanx (Figure 2). Severe tenderness over the distal volar pulp on palpation and minimal discharge from the entry site of the splinter. Surgical treatment was decided, and a written informed consent was obtained from the patient.

Surgery and follow-up were performed by two hand surgeons of our clinic. During surgery, debridement and curettage were performed, and partial excision of the distal phalanx at an appropriate level was done (Figure 3). Postoperative radiographs confirmed the partial excision of the distal phalanx at an appropriate level (Figure 4). Gram staining of the specimens collected intraoperatively showed an abundant number of neutrophils (polymorphonuclear neutrophil leukocytes) with no microorganism. Bacterial and fungal cultures were incubated and regular-shaped colonies with white to cream color were seen at $72 \mathrm{~h}$ of incubation in the blood agar and sabouraud dextrose agar. Using the matrix-assisted laser desorption/ionization time of flight mass spectrometry (MALDI-TOF-MS; VITEK ${ }^{\circledR}$; bioMérieux Diagnostics, France), C. Iusitaniae was isolated. The antifungal susceptibility was tested via the VITEK $^{\circledR} 2$ (bioMérieux Diagnostics, France) antimicrobial susceptibility testing. The culture analysis showed production of C. Iusitaniae and the pathological examination result was reported as superficial tissue characterized by parakeratosis and squamous hyperplasia. Postoperative laboratory testing showed normal ESR and CRP levels with a
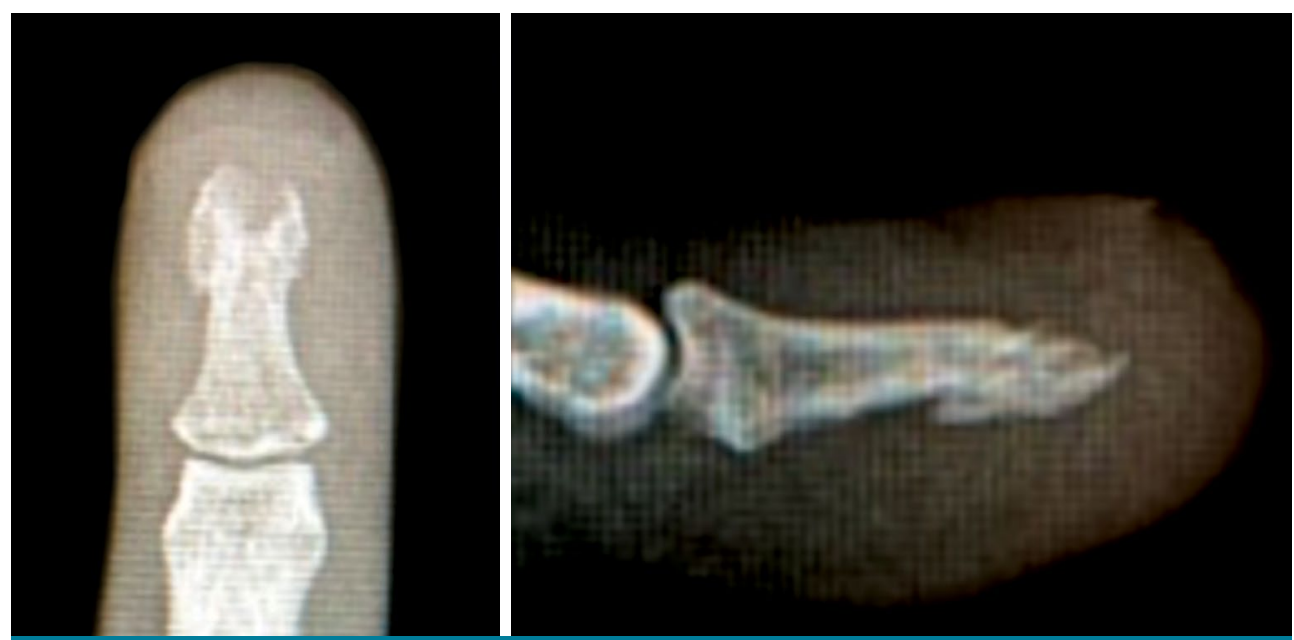

FIGURE 2. Anteroposterior and lateral radiographs showing local osteolysis due to osteomyelitis of distal phalanx. 

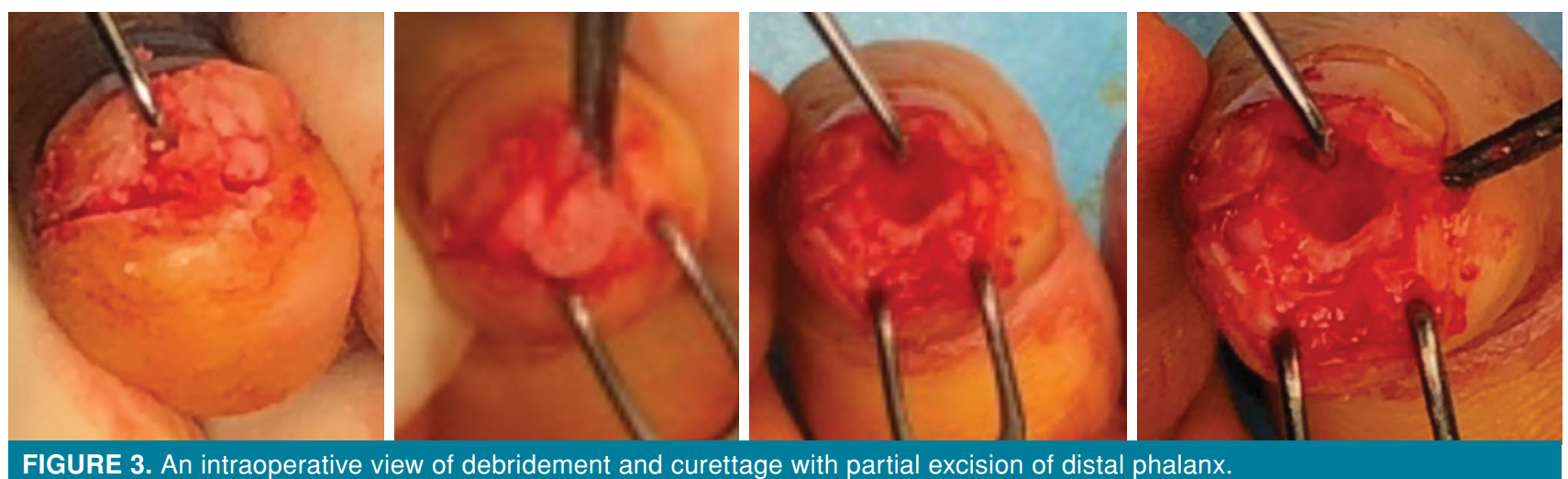

FIGURE 3. An intraoperative view of debridement and curettage with partial excision of distal phalanx.

WBC count of $9,500 / \mathrm{mm}^{3}$. The patient was consulted to the infectious diseases clinic and fluconazole 100 mg Po (Triflucan ${ }^{\circledR}$, Pfizer İlaçları Ltd. Şti., Istanbul, Turkey) for three weeks was initiated. Wound dressing was applied every three days and sutures were removed at three weeks. During follow-up visits at three and six weeks, and three months, near-excellent results were achieved. At the end of three months, physical examination revealed full active range of motion of the phalangeal joint. The patient is still free from pain or discharge on later follow-up visits.

The patient and/or her family were informed that data from the case would be submitted for publication and gave their consent.

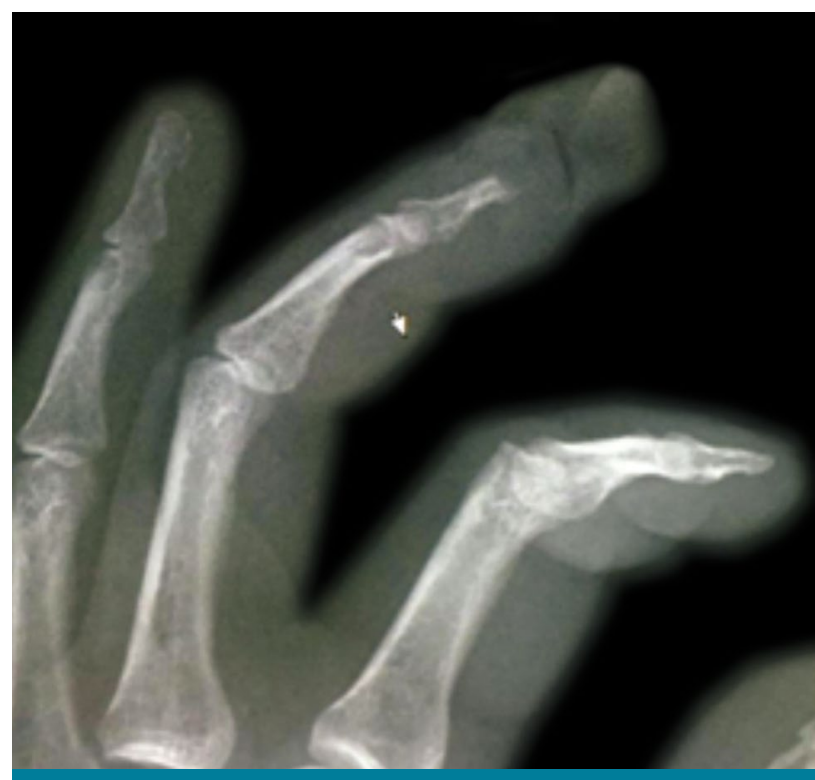

FIGURE 4. A postoperative oblique radiograph confirming the partial excision of distal phalanx at an appropriate level.

\section{DISCUSSION}

Candida osteomyelitis of the bones has been very rarely reported in the literature. ${ }^{[14,15]}$ There are also case reports of osteomyelitis of the distal phalanges. ${ }^{[16,17]}$ In the literature, the first case of osteomyelitis of the distal humerus caused by C. lusitaniae was a premature infant. ${ }^{[18]}$ In addition, a case series of Candida osteomyelitis including 207 pediatric and adult patients was previously reported; however, the involvement site of osteomyelitis was undetermined. ${ }^{[8]}$ There are also several case reports of olecranon bursitis and septic arthritis caused by C. Iusitaniae. ${ }^{[19,20]}$ To the best of our knowledge, our case is the first case of osteomyelitis of the distal phalanx caused by C. Iusitaniae in the literature in which its diagnosis and treatment were discussed in detail. ${ }^{[21]}$

In the majority of cases, laboratory testing yields non-specific results with slightly elevated ESR and CRP levels, and leukocytosis in only 35\% of patients. ${ }^{[22,23]}$ In addition, plain radiography typically shows bone tissue alterations such as periosteal reaction and destruction 10 to 12 days after the infection. ${ }^{[24]}$ Although combination therapy of voriconazole and posaconazole can be used in the treatment of infections caused by C. Iusitaniae ${ }^{[25]}$ fluconazole $6 \mathrm{mg} / \mathrm{kg}$ for six weeks is usually administered. ${ }^{[26]}$ In our case, similarly, pre- and postoperative ESR and CRP levels were normal. However, the preoperative WBC count increased, while it tended to decrease after surgery. Fortunately, plain radiographs demonstrated specific findings compatible with $C$. lusitaniae infections, since the patient was admitted to our clinic about 45 days after the injury. Unlike the literature, however, the fluconazole treatment was recommended by the infectious diseases clinic for three weeks. During follow-up in the outpatient setting, no pain or 
discharge was observed, which underscores the use of adequate antibiotherapy in our case.

In conclusion, osteomyelitis should be considered in patients with splinter injuries suffering from persistent pain and discharge despite long-term antibiotic use. This case is the first report of osteomyelitis of the distal phalanx caused by $C$. Iusitaniae in the literature, highlighting the importance of definitive diagnosis and pathogen-specific treatment, rather than empirical treatment, to achieve favorable results with cure.

\section{Declaration of conflicting interests}

The authors declared no conflicts of interest with respect to the authorship and/or publication of this article.

\section{Funding}

The authors received no financial support for the research and/or authorship of this article.

\section{REFERENCES}

1. Reilly KE, Linz JC, Stern PJ, Giza E, Wyrick JD. Osteomyelitis of the tubular bones of the hand. J Hand Surg Am 1997;22:644-9.

2. Waldvogel FA, Medoff G, Swartz MN. Osteomyelitis: a review of clinical features, therapeutic considerations and unusual aspects. N Engl J Med 1970;282:198-206.

3. Stone $\mathrm{NH}$, Hursch $\mathrm{H}$, Humphrey $\mathrm{CR}$, Boswick JA Jr. Empirical selection of antibiotics for hand infections. J Bone Joint Surg [Am] 1969;51:899-903.

4. Gürbüz K. The treatment of onychogryphosis of hand nails by total matricectomy and dorsal V-Y advancement flap. Jt Dis Relat Surg 2020;31:39-42.

5. Jaime-Villalonga A, Saul Z, Miljkovic G. Mycobacterium arupense finger osteomyelitis: Case report. Int J Infect Dis 2020;92:226-7.

6. Raval P. Phalangeal Osteomyelitis Caused by Staphylococcus lugdunensis - A Case Report of a Rare Association and Review of Literature. J Orthop Case Rep 2019;9:70-3.

7. Slenker AK, Keith SW, Horn DL. Two hundred and eleven cases of Candida osteomyelitis: 17 case reports and a review of the literature. Diagn Microbiol Infect Dis 2012;73:89-93.

8. Gamaletsou MN, Kontoyiannis DP, Sipsas NV, Moriyama B, Alexander E, Roilides E, et al. Candida osteomyelitis: analysis of 207 pediatric and adult cases (1970-2011). Clin Infect Dis 2012;55:1338-51.

9. Lopez R, Hunter AR, Geoghegan O, Demertzi E. Candida parapsilosis osteomyelitis. BMJ Case Rep 2014;2014:bcr2014206520.

10. Viudes A, Pemán J, Cantón E, Salavert M, Ubeda P, LópezRibot JL, et al. Two cases of fungemia due to Candida lusitaniae and a literature review. Eur J Clin Microbiol Infect Dis 2002;21:294-9.

11. Merz WG. Candida lusitaniae: frequency of recovery, colonization, infection, and amphotericin B resistance. J Clin Microbiol 1984;20:1194-5.

12. Ono R, Komura S, Hirakawa A, Hirose H, Tsugita M, Masuda T, et al. Staged arthrodesis using the Masquelet technique for osteomyelitis of the finger with articular destruction: a report of two cases. Arch Orthop Trauma Surg 2019;139:1025-31.

13. Pruzansky ME, Lee Y, Pruzansky J. Masquelet Technique for Phalangeal Reconstruction and Osteomyelitis. Tech Hand Up Extrem Surg 2020. [Online ahead of print]

14. McLeod N, Fisher M, Lasala PR. Vertebral osteomyelitis due to Candida species. Infection 2019;47:475-8.

15. Arias F, Mata-Essayag S, Landaeta ME, Capriles $\mathrm{CH}$, Pérez C, Núñez MJ, et al. Candida albicans osteomyelitis: case report and literature review. Int J Infect Dis 2004;8:307-14.

16. Toki S, Hibino N, Sairyo K, Takahashi M, Yoshioka S, Yamano M, et al. Osteomyelitis Caused by Candida glabrata in the Distal Phalanx. Case Rep Orthop 2014;2014:962575.

17. Schmutz N, Adler T, Schelhorn N, Wirz S, Fricker R. Postoperative Osteomyelitis of a Distal Phalanx Caused by Raoultella ornithinolytica. Handchir Mikrochir Plast Chir 2016;48:175-8.

18. Oleinik EM, Della-Latta P, Rinaldi MG, Saiman L. Candida lusitaniae osteomyelitis in a premature infant. Am J Perinatol 1993;10:313-5.

19. Behar SM, Chertow GM. Olecranon bursitis caused by infection with Candida lusitaniae. J Rheumatol 1998;25:598-600.

20. Bariola JR, Saccente M. Candida lusitaniae septic arthritis: case report and review of the literature. Diagn Microbiol Infect Dis 2008;61:61-3.

21. Atik OŞ. Is there something new and interesting in my article? Eklem Hastalik Cerrahisi 2019;30:69.

22. Grimbly C, Odenbach J, Vandermeer B, Forgie S, Curtis S. Parenteral and oral antibiotic duration for treatment of pediatric osteomyelitis: a systematic review protocol. Syst Rev 2013;2:92.

23. Couto-Gonzalez I, Brea-García B, Taboada-Suárez A. Purulent infection in the third finger with associated osteomyelitis. BMJ Case Rep 2013;2013:bcr2012008476.

24. Ferroni A, Al Khoury H, Dana C, Quesne G, Berche P, Glorion C, et al. Prospective survey of acute osteoarticular infections in a French paediatric orthopedic surgery unit. Clin Microbiol Infect 2013;19:822-8.

25. Sanchis M, Guarro J, Sutton DA, Fothergill AW, Wiederhold $\mathrm{N}$, Capilla J. Voriconazole and posaconazole therapy for experimental Candida lusitaniae infection. Diagn Microbiol Infect Dis 2016;84:48-51.

26. Pappas PG, Rex JH, Sobel JD, Filler SG, Dismukes WE, Walsh TJ, et al. Guidelines for treatment of candidiasis. Clin Infect Dis 2004;38:161-89. 